\title{
Effect of Palmitic Acid in the Acceleration of Polyethylene Biodegradation by Aspergillus oryzae
}

\author{
Vijayasree Jayaprakash and Uma Maheswari Devi Palempalli* \\ Department of Applied Microbiology, Sri Padmavati Mahila Visvavidyalayam, Tirupati - 517 502, India.
}

\begin{abstract}
The biodegradation of High Density Polyethylene (HDPE) and Low Density Polyethylene (LDPE) by Aspergillus oryzae was examined in the current study. The optimal temperature, $\mathrm{pH}$, favorable carbon and nitrogen sources for organism growth were determined. A comparative study of degradation in surface sterilized and palmitic acid treated polyethylenes was done to learn the effect of the surfactant fatty acid on the polymer. The films degraded by Aspergillus oryzae strain were analyzed by weight loss, FTIR, SEM studies and degree of water absorption (swelling index). The organism showed 33\% weight loss of black coloured HDPE and $40 \%$ weight loss of green coloured LDPE in 90 days after palmitic acid treatment.
\end{abstract}

Keywords: HDPE, LDPE, Aspergillus oryzae, biodegradation.

*Correspondence: jvijayasree89@gmail.com,+91-7093805049; umadevi66@yahoo.co.in;

(Received: 02 October 2018; accepted: 15 November 2018)

Citation: Vijayasree Jayaprakash, Uma Maheswari Devi Palempalli, Effect of Palmitic Acid in the Acceleration of Polyethylene Biodegradation by Aspergillus oryzae, J Pure App/ Microbiol., 2018; 12(4):2259-2268. http://dx.doi.org/10.22207/JPAM.12.4.66

(c) The Author(s) 2018. Open Access. This article is distributed under the terms of the Creative Commons Attribution 4.0 International License which permits unrestricted use, sharing, distribution, and reproduction in any medium, provided you give appropriate credit to the original author(s) and the source, provide a link to the Creative Commons license, and indicate if changes were made. 


\section{INTRODUCTION}

The use of plastics in today's world has become inevitable. Though life without plastics is unimaginable, its regular use by a population of 7.5 billion of this planet is creating havoc. The organic polymer synthesized from petroleum derivatives is utilized in almost all industries including food industry, pharmaceutical, automobile, electrical and electronics, toy, furniture etc. An accelerated decrease in petroleum products may be attributed to extreme usage of plastics. This results in diminishing petroleum resources which is nonrenewable. Further, accumulation of plastics in the atmosphere leads to disastrous effects.

Plastics cannot be incinerated like other wastes. On burning plastics, substances like dioxins, mercury, furans, halogens which are toxic and carcinogenic are released causing deleterious effects to plants, animals, humans and nature ${ }^{1}$. The other options in management of plastics are - recycling, biodegradation and bioplastics.

Recycling has its own demerits. Recycling of plastics from municipal waste is a very laborious, expensive and time taking process. Since each plastic product differs in its chemistry from others it may interfere in the process of recycling. A proper sorting of plastic products is recommended for recycling. The differing melting temperatures of various kinds of plastics intervene in the procedure which may lead to loss of the product. Further, there are chances of liberation of toxic gases as the plastics are retreated ${ }^{2}$.

Bioplastics is the best option to free this atmosphere from ill effects of plastics. Since natural products are used in the manufacture, the plastic products would readily degrade after disposal. But bioplastics may not be durable like synthetic plastics. Few bioplastics which are degradable by microorganisms are polycaprolactone, poly butyl succinate, poly hydroxy butyrate, polylactides, starch blends ${ }^{3}$. Though bioplastics serve as the best option, the synthetic plastics which are already in the atmosphere have to be eliminated. When incineration is harmful and recycling is tedious, biodegradation is the only choice for the decimation of plastics.

Many studies have shown that various microorganisms are capable of deforming the structure of polyethylene, most of them being pathogenic strains belonging to genera Pseudomonas, Streptococcus, Staphylococcus, Bacillus, Aspergillus, Fusarium etc. which might in turn lead to infectious diseases ${ }^{4}$. Hence there is a need to employ a non pathogen which could efficiently degrade polyethylene.

As per chemical resistance chart provided by Spilltech and Sunwest contianers, US ${ }^{5,6}$, on storing palmitic acid in polyethylene bags or containers, physical properties of polyethylene alter as the polymer is not compatible with the fatty acid. On these grounds, palmitic acid has been used as the substrate to pretreat polyethylene before degradation with the organism.

\section{MATERIALS AND METHODS}

To study the biodegradation, two kinds of commercially available polyethylene bags were chosen - black colored high density polyethylene (HDPE) and green colored low density polyethylene (LDPE). The fungus, Aspergillus oryzae was isolated from the polyethylene bags buried in the soil for six months. Focus was laid on the fungal strain based on the affinity exhibited by it towards the plastic. The strain was isolated, subcultured and maintained on Potato dextrose medium. The fungus was identified as Aspergillus oryzae by macroscopic, microscopic and molecular characterization.

\section{Determination of optimal conditions for the growth of A.oryzae}

The isolated fungus (A.oryzae) was tested for its optimal conditions of growth at varying values of physical factors such as $\mathrm{pH}$ and temperature.

$\mathrm{pH}$

The favourable $\mathrm{pH}$ of the A.oryzae strain was determined by incubating the isolate in Potato dextrose broth at $\mathrm{pH}$ ranging from 4 to 8 at $28 \pm 2^{\circ} \mathrm{C}$ for 5 days. The dry mass of the mycelial mat was noted down.

\section{Temperature}

The A.oryzae strain was grown in potato dextrose broth for 5 days at different temperatures ranging from $25^{\circ} \mathrm{C}$ to $45^{\circ} \mathrm{C}$ to find out its desirable temperature. After 5 days of incubation, the mycelial mat was recovered from the flasks, dried to remove the moisture content and the mycelial masses were noted down. 


\section{Effect of carbon and nitrogen sources on Aspergillus oryzae}

The Czapek dox broth devoid of any carbohydrate was supplemented with different carbon and nitrogen sources to check their effect on the growth of A.oryzae. The medium was composed by the following chemicals-

Di potassium hydrogen phosphate 1

Iron sulfate. Heptahydrate

\section{$1 \mathrm{~g}$}

$0.01 \mathrm{~g}$

Magnesium sulfate. heptahydrate $\quad 0.5 \mathrm{~g}$

Potassium chloride

$0.5 \mathrm{~g}$

Sodium nitrate

$3 \mathrm{~g}$

Agar

Distilled water

$\mathrm{pH}$

$15 \mathrm{~g}$

$1000 \mathrm{ml}$

7.3

Sucrose was not added to the medium, unlike the conventional Czapek dox medium, to ensure the nutritional dependence of the organism on carbon content of the polymer.

The various carbon sources used were molasses, potato hydrolysate, dextrose, starch, sucrose, fructose and malt extract in 1\% concentration. The nitrogen sources used were peptone, yeast extract, soya meal, ammonium sulfate, urea, beef extract and potassium nitrate in $1 \%$ concentration.The flasks were incubated for 5 days. The biomass of A.oryzae was recorded after removing the moisture in them.

Pretreatment of polyethylene bags with ethanol and palmitic acid

The polyethylene bags were cut into $2 \mathrm{~cm}$ diameter discs. The discs or films were surface sterilized by $80 \%$ ethanol for 2 hours, washed with distilled water and dried overnight. The sterile discs of the LDPE and HDPE bags were transferred to $100 \mathrm{ml}$ of Potato dextrose broth and Czapek Dox broth (without carbon source, as mentioned in the previous section) separately and inoculated with Aspergillus oryzae for 90 days. The films were intermittently checked for weight loss for every 30 days.

The second set of LDPE and HDPE films were sterilized and pretreated overnight with $1 \%$ palmitic acid dissolved in 2-propanol. These films were added to the Potato dextrose broth and Czapek dox broth and inoculated with Aspergillus oryzae for 90 days. The weight loss of the films was determined for every 30 days.

\section{Biodegradation analysis}

\section{Calculation of percentage of weight loss}

The polyethylene discs were washed with $2 \%$ Sodium dodecyl sulphate for $4 \mathrm{hrs}$ to remove all mycelial debris ${ }^{7}$, sterilized with ethanol and finally washed with distilled water before weighing. The percentage weight loss of a mean of five samples has been provided in the results which was calculated using the following formula ${ }^{8}$.

Weight loss $(\%)=\frac{\text { initial weight }- \text { final weight }}{\text { initial weight }} \times 100$

\section{Fourier Transform Infrared spectroscopy}

FTIR is an effective tool to determine the change, appearance and disappearance of functional groups in a polymer ${ }^{9}$. The differences in the structure of surface sterilized polyethylene and palmitic acid treated polyethylene incubated with the fungus were studied after 90 days. The surface sterilized and palmitic acid treated polyethylene samples were placed in the sample holder plate as such and the FTIR analysis (BRUKER model ALPH) with 32 scans in the range of $4000 \mathrm{~cm}^{-1}$ to $400 \mathrm{~cm}^{-1}$ at a resolution of $2 \mathrm{~cm}^{-1}$ was performed. The percentage of transmittance through the polyethylene samples were evaluated by FTIR at signatures of corresponding functional groups. Therefore, a comparative study can be made between the controls and degraded samples for the detection of changes in the functional groups.

\section{Scanning electron microscopy}

For SEM investigations, Karl Zeiss instrument was used. The eroded polyethylene specimens were fixed with $2.5 \%$ glutaraldehyde in $0.05 \mathrm{M}$ cacodylate buffer for 90 minutes at $4^{\circ} \mathrm{C}$. The samples were sputter coated for 75 seconds with gold particles after dehydration. The gold coated polymer samples were placed on the microscopic stage to visualize their weathering after incubation with A.oryzae.

Determination of degree of water absorption by LDPE and HDPE

The ability of the hydrophobic polyethylene films to absorb water after undergoing biodegradation with A.oryzae was studied by Ljerka Kratofil Krehula et al.,2013 method ${ }^{10}$. The HDPE and LDPE films, both control and A.oryzae 
treated samples were weighed before immersing in water. The films were immersed in water for 120 hours at $40^{\circ} \mathrm{C}$. The masses of the polymers were measured intermittently at 24 hours, 72 hours and 120 hours. The difference in weights of the samples testifies the uptake of moisture content by the plastics. The degree of water absorption $(\alpha)$ was calculated using the following formula.

$$
\alpha(\%)=\frac{100\left(m_{2}-m_{1}\right)}{m_{1}}
$$

where $\alpha=$ water absorption degree, $\%$

$\mathrm{m}_{2}=$ mass after swelling, $\mathrm{g}$

$\mathrm{m}_{1}=$ mass before swelling, $\mathrm{g}$

\section{RESULTS AND DISCUSSION \\ Morphology of Aspergillus oryzae}

The fungus isolated from plastic burial site was categorized as A.oryzae based on mycelial morphology, spore formation and molecular characterization. The morphology of Aspergillus oryzae is shown in Fig 1.

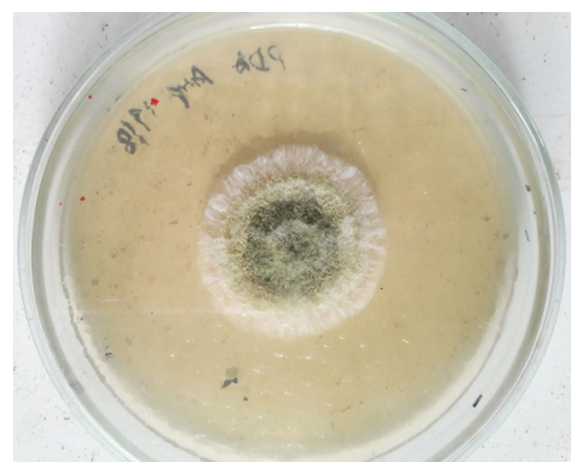

Fig. 1. A.oryzae cultured on PDA plate

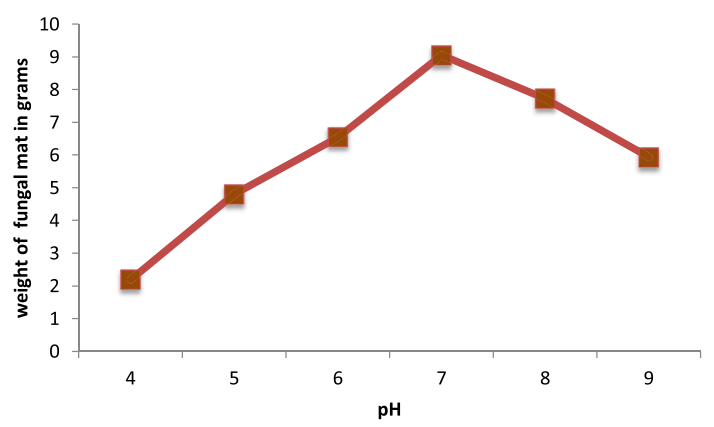

Fig. 2. Effect of $\mathrm{pH}$ on growth of A.oryzae
Optimal conditions for the growth of A.oryzae

The optimum $\mathrm{pH}$ and temperature for the luxuriant growth of A.oryzae was found to be 7.0 and $30^{\circ} \mathrm{C}$ respectively. Therefore, the isolated fungus was maintained at the same $\mathrm{pH}$ and temperature (Figures $2 \& 3$ ). Molasses and soya meal (natural sources) were found to be the best carbon and nitrogen sources for the growth of A.oryzae. (Figures 4 \& 5). In both cases, Aspergillus oryzae preferred natural sources over other chemicals for its growth.

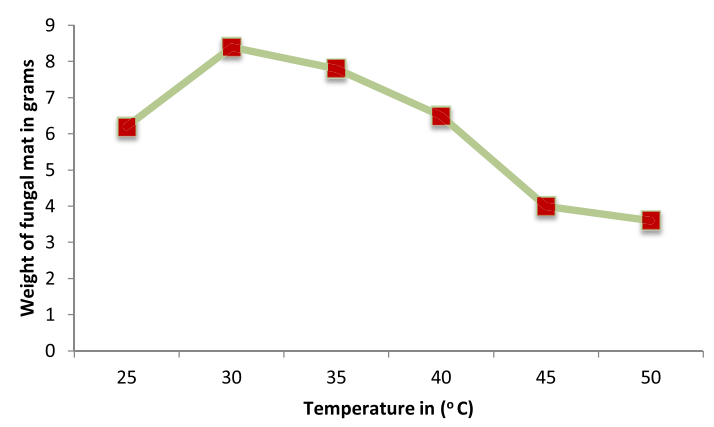

Fig. 3. Effect of temperature on growth of A.oryzae

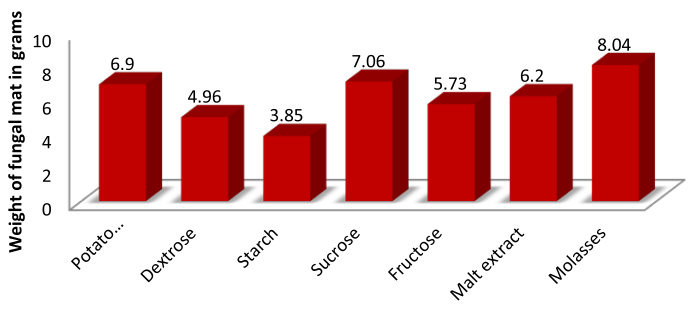

Fig. 4. Suitable carbon source for the growth of A.oryzae

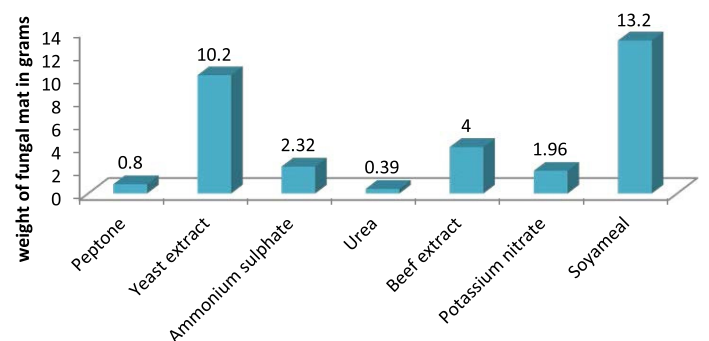

Fig. 5. Effect of nitrogen supplementation on growth of A.oryzae 


\section{Biodegradation analysis Weight loss determination}

The films of HDPE and LDPE retrieved every 30 days showed a gradual decline in weights. The results are tabulated in Table 1.

The effect of medium used for degradation of the polyethylene samples with A.oryzae was clearly noticed. The results depict the utilization of polyethylene as carbon source in Czapek dox medium, which was not supplemented with any carbon while the luxuriant growth of A.oryzae in Potato dextrose broth may be attributed to the nutrients present in the medium. Hence Czapek dox medium enabled the growth of the fungus around the polymer, enhancing its degradation. The degradation percentage of HDPE discs was $22.6 \%$ in Potato dextrose medium while it is $28 \%$ in Czapek dox medium. The fungus in Potato dextrose medium was able degrade $25 \%$ of LDPE whereas the same fungal strain i.e., A.oryzae degraded $32.5 \%$ when incubated in Czapek dox medium
(Table 1). Therefore, Czapek dox broth turned out to be a better medium for the degradation to happen.

The pretreatment of polyethylene films with palmitic acid gave positive results on degradation. After 90 days incubation of the HDPE plastics, $33 \%$ of degradation was achieved in Czapek dox medium and $24 \%$ in potato dextrose medium. On the other hand, the percentage of degradation of LDPE films in Czapek dox medium was noted as $40 \%$, and $30 \%$ in potato dextrose broth.. A brief comparison between the degradation percentages of palmitic acid pretreated and surface sterilized polyethylenes in Czapek dox medium shows $5 \%$ rise in HDPE and 7.5\% rise in LDPE (Fig 6 \& Fig 7).

On the whole, palmitic acid treated polyethylene incubated with Aspergillus oryzae in Czapek dox medium proved to elevate the rate of degradation.

Table 1. Table showing percentage weight loss of polyethylene films after incubation with Aspergillus oryzae in Potato dextrose broth (PDB) and Czapek dox broth (CDB)

\begin{tabular}{|c|c|c|c|c|c|c|c|}
\hline & & \multicolumn{3}{|c|}{$\begin{array}{l}\text { Percentage of weight loss } \\
\text { in black HDPE }\end{array}$} & \multicolumn{3}{|c|}{$\begin{array}{l}\text { Percentage of weight loss } \\
\text { in green LDPE }\end{array}$} \\
\hline & & 30 days & 60 days & 90 days & 30 days & 60 days & 90 days \\
\hline \multirow{2}{*}{$\begin{array}{l}\text { Surface sterilized } \\
\text { with ethanol }\end{array}$} & PDB & 8 & 14.6 & 22.6 & 7.4 & 12.4 & 25 \\
\hline & $\mathrm{CDB}$ & 9.3 & 18.6 & 28 & 10 & 22.4 & 32.5 \\
\hline \multirow{2}{*}{$\begin{array}{l}\text { Preteated with } \\
\text { palmitic acid }\end{array}$} & PDB & 6.6 & 15 & 24 & 7.4 & 19.8 & 30 \\
\hline & $\mathrm{CDB}$ & 12 & 21 & 33 & 14 & 26 & 40 \\
\hline
\end{tabular}

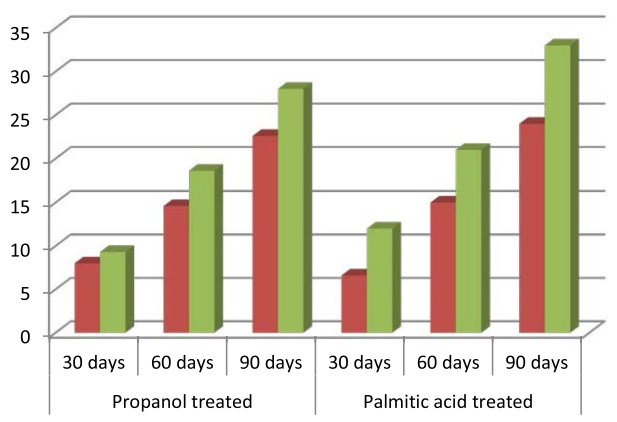

Fig. 6. Percentage of degradation of surface sterilized and palmitic acid treated black HDPE in Potato dextrose medium and Czapek dox medium

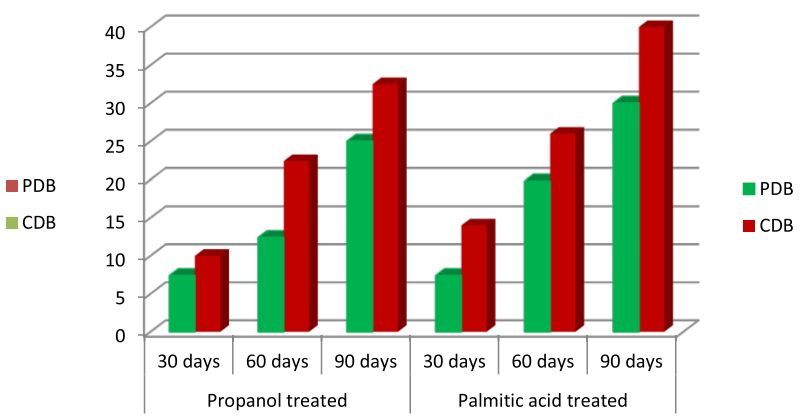

Fig. 7. Percentage of degradation of surface sterilized and palmitic acid treated green LDPE in potato dextrose medium and Czapek dox medium 


\section{Fourier Transform Infrared Spectroscopy FTIR analysis of black HDPE}

The control of the black film on FTIR analysis showed important peaks at $2928.80 \mathrm{~cm}$ $1,2850.70 \mathrm{~cm}^{-1}, 1465.13 \mathrm{~cm}^{-1}, 1373.30 \mathrm{~cm}^{-1}$ etc. which represent functional groups like $\mathrm{C}-\mathrm{H}$ (stretch) of alkane and $\mathrm{C}-\mathrm{H}$ bending of alkane (Fig 8). Since many chemical compounds (pigments, plasticizers etc.) contribute in the synthesis of polyethylene bags, other than polyethylene itself, many peaks were noticed at $3606.26 \mathrm{~cm}^{-1}$ and $2659.29 \mathrm{~cm}^{-1}$ indicating $\mathrm{O}-\mathrm{H}$ stretch of alcohols, $1304.01 \mathrm{~cm}^{-1}$ for $\mathrm{C}-\mathrm{O}$ stretch of ester, $1163 \mathrm{~cm}^{-1}$ representing $\mathrm{C}-\mathrm{O}$ stretch of tertiary alcohol etc. The peaks of surface sterilized HDPE film shifted from $2928.80 \mathrm{~cm}^{-1}$ to $2921.63 \mathrm{~cm}^{-1}$ and 2850.70 $\mathrm{cm}^{-1}$ to $2851.17 \mathrm{~cm}^{-1}$. The peak $2659.29 \mathrm{~cm}^{-1}$ was not seen in ethanol treated HDPE. The peak at $1465.13 \mathrm{~cm}^{-1}$ in control shifted to $1464.39 \mathrm{~cm}^{-1}$ and $1373.30 \mathrm{~cm}^{-1}$ peak moved to $1375.27 \mathrm{~cm}^{-1}$ demonstrating changes in stretching and bending of $\mathrm{C}-\mathrm{H}$ bond of alkanes which are significant for the breakdown of polyethylene. The $1304.01 \mathrm{~cm}^{-1}$ peak disappeared in ethanol treated sample and formation of new peak was noticed at $1597.04 \mathrm{~cm}^{-1}$ which corresponds to $-\mathrm{C}=\mathrm{C}$ - aromatic stretch (Fig 9). In the HDPE samples pretreated with palmitic acid, owing to the oxidation of polymer, new peaks at $1719.95 \mathrm{~cm}^{-1}, 1576.04 \mathrm{~cm}^{-1}$ and $1540.14 \mathrm{~cm}^{-1}$ were seen. The peaks indicate the formation of carbonyl groups ( $\mathrm{C}=\mathrm{O}$ stretch) in the sample and the peaks at $1576.04 \mathrm{~cm}^{-1}$ and $1540.14 \mathrm{~cm}^{-1}$ are due to aromatic stretch of $-\mathrm{C}=\mathrm{C}-$. The other peaks lost in palmitic acid treated sample are $3606.26 \mathrm{~cm}^{-1}$ and $2659.29 \mathrm{~cm}^{-1}$. The shifts of peaks from 2928.80 $\mathrm{cm}^{-1}$ to $2922.37 \mathrm{~cm}^{-1}, 1465.13 \mathrm{~cm}^{-1}$ to $1463.89 \mathrm{~cm}^{-1}$, $1373.30 \mathrm{~cm}^{-1}$ to $1376.24 \mathrm{~cm}^{-1}, 1304.01$ to 1272.11 $\mathrm{cm}^{-1}$ are evidences for the significant changes that happened in the process of degradation of polyethylene (Fig 10).

\section{FTIR analysis of green LDPE}

The control sample of LDPE film showed three peaks at $2921.59 \mathrm{~cm}^{-1}, 2851.16 \mathrm{~cm}^{-1}, 1464.05$ $\mathrm{cm}^{-1}$ (Fig 11) whereas the surface sterilized green films developed four new peaks at 1720.30 $\mathrm{cm}^{-1}, 1375.70 \mathrm{~cm}^{-1}, 1267.70 \mathrm{~cm}^{-1}, 1019.57 \mathrm{~cm}^{-1}$ confirming the formation of carbonyl groups, phenols, alcohols etc. A slight shift in peaks of $2921.59 \mathrm{~cm}^{-1}$ to $2923.35 \mathrm{~cm}^{-1}, 2851.16 \mathrm{~cm}^{-1}$ to $2850.67 \mathrm{~cm}^{-1}$ and $1464.05 \mathrm{~cm}^{-1}$ to $1463.56 \mathrm{~cm}^{-1}$ were observed. These peaks represent stretch and bending of alkanes. This can be presumed as the perturbations caused because of $A$.oryzae feeding on the film (Fig 12). The LDPE pretreated with palmitic acid showed additional peaks at 3605.17 $\mathrm{cm}^{-1}, 2659.66 \mathrm{~cm}^{-1}, 2020.23 \mathrm{~cm}^{-1}, 1606.98 \mathrm{~cm}^{-1}$, $1534.40 \mathrm{~cm}^{-1}, 1369.83 \mathrm{~cm}^{-1}, 1025.28 \mathrm{~cm}^{-1}$ etc. These peaks are resultant of generation of free $\mathrm{O}-\mathrm{H}$ groups, aldehydes, nitriles, $\mathrm{C}=\mathrm{C}$ stretching, $\mathrm{C}-\mathrm{H}$ bending of alkanes, C-O stretching. The 2921.59 $\mathrm{cm}^{-1}$ peak shifted to $2931.76 \mathrm{~cm}^{-1}$ indicating the alterations occuring in $\mathrm{C}-\mathrm{H}$ bonds of alkanes (Fig 13).

\section{Scanning electron microscopy}

The control films of HDPE and LDPE bags featured plain, smooth and even surfaces (Fig 14 \& Fig 15). The SEM studies revealed rough surfaces in palmitic acid treated and surface sterilized polyethylene films incubated with A.oryzae. Though the surface sterilized polyethylene films exhibited cracks and rugged surface (Fig 16 \& Fig 17), the palmitic acid treated polyethylene films on visualization under SEM presented more fractures, fissures and the films were completely deformed

Table 2. Table showing increase in polyethylene film masses after water absorption

\begin{tabular}{|c|c|c|c|c|c|}
\hline \multicolumn{2}{|c|}{ Type of polyethylene film } & \multicolumn{4}{|c|}{$\begin{array}{l}\text { Mass of polyethylene films at } \\
\text { various intervals in } \mathrm{mg}\end{array}$} \\
\hline & & $0 \mathrm{hrs}$ & $24 \mathrm{hrs}$ & $72 \mathrm{hrs}$ & $120 \mathrm{hrs}$ \\
\hline \multirow[t]{3}{*}{ Black HDPE } & Control & 5.0 & 5.0 & 5.0 & 5.0 \\
\hline & Surface sterilized & 5.0 & 5.05 & 5.22 & 5.45 \\
\hline & Palmitic acid treated & 5.0 & 5.08 & 5.31 & 5.63 \\
\hline \multirow[t]{3}{*}{ Green LDPE } & Control & 3.0 & 3.0 & 3.0 & 3.01 \\
\hline & Surface sterilized & 3.0 & 3.05 & 3.29 & 3.53 \\
\hline & Palmitic acid treated & 3.0 & 3.10 & 3.42 & 3.75 \\
\hline
\end{tabular}


(Fig 18 \& Fig 19), particularizing the effect of the fatty acid in polyethylene degradation.

\section{Determination of degree of water absorption by LDPE and HDPE}

The uptake of moisture resulted in swelling of the polymer samples which in turn increased their weights. Being hydrophobic, the untreated control samples could not absorb any moisture and hence their masses remained unchanged. The surface sterilized HDPE and LDPE could absorb $9 \%$ and $17.6 \%$ of water while palmitic acid coated polyethylene films exhibited further

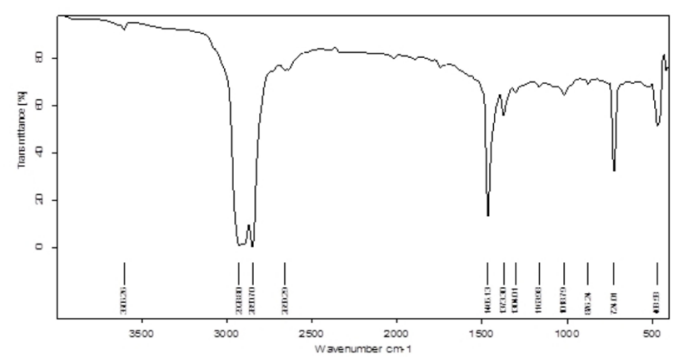

Fig. 8. FTIR analysis of Black HDPE control

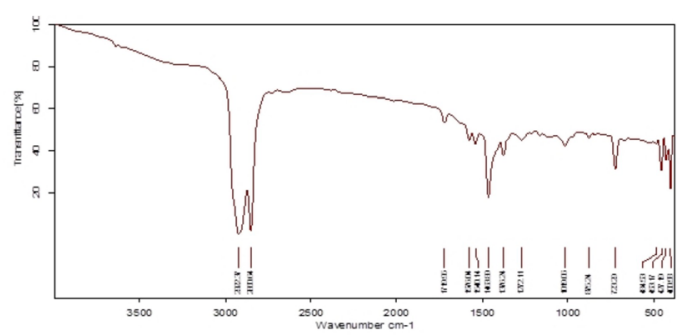

Fig. 10. FTIR analysis of palmitic acid treated black HDPE

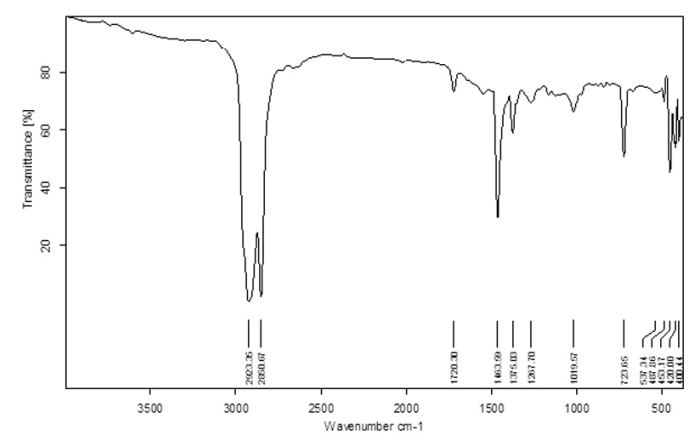

Fig. 12. FTIR signatures of surface sterilized LDPE treated with A.oryzae rise in their masses. The highest percentage of water absorption in LDPE and HDPE were observed in palmitic acid treated polyethylene after 120 days which was $12.6 \%$ in black HDPE and $25 \%$ in green LDPE, expressing the ease of water absorption by LDPE than HDPE. The palmitic acid pretreatment of the polymer showed a notable rise in weights after water absorption which might be due to the reduction in interfacial tension and utilization of the fatty acid as substrate for the growth of fungus, thereby accelerating the degradation process.

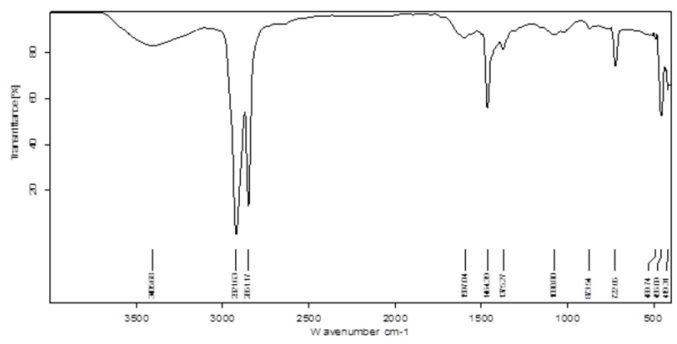

Fig. 9. FTIR analysis of surface sterilized black HDPE

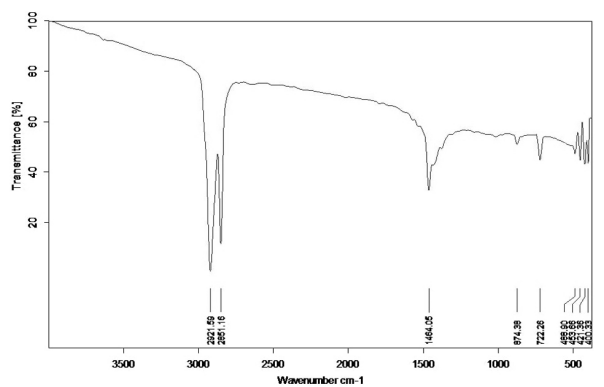

Fig. 11. FTIR analysis of green LDPE control

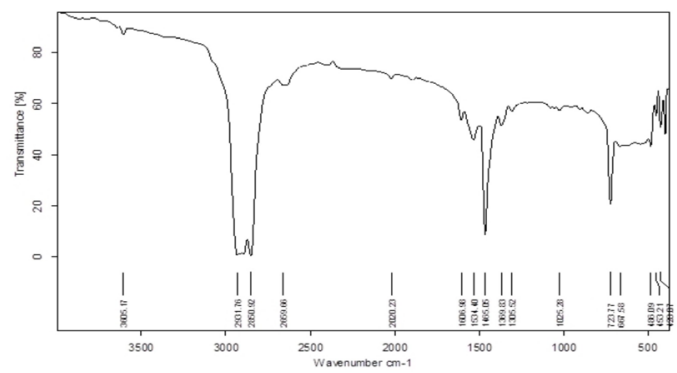

Fig. 13. Changes in signatures of palmitic acid pretreated green LDPE 


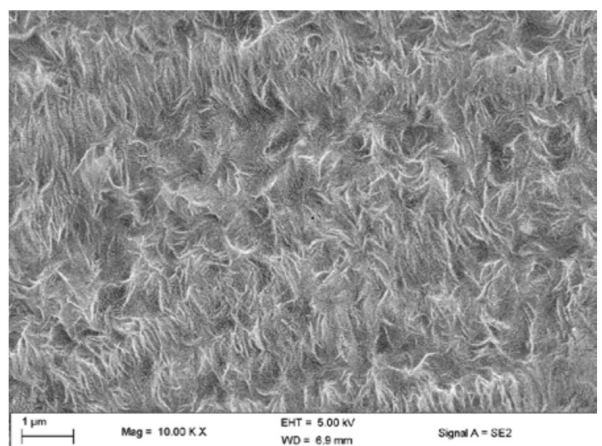

Fig. 14. Black HDPE control

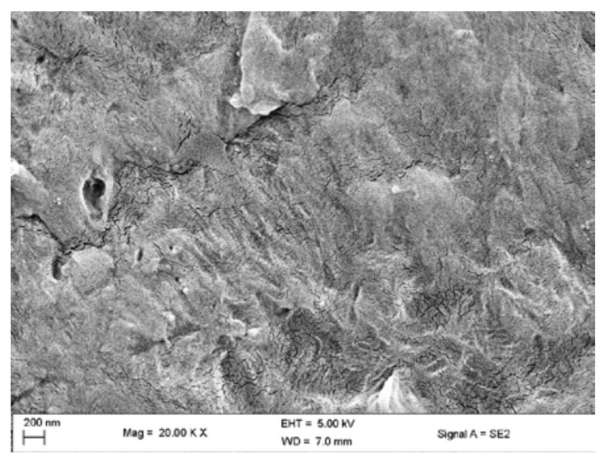

Fig. 16. Degradation in Surface sterilized black HDPE

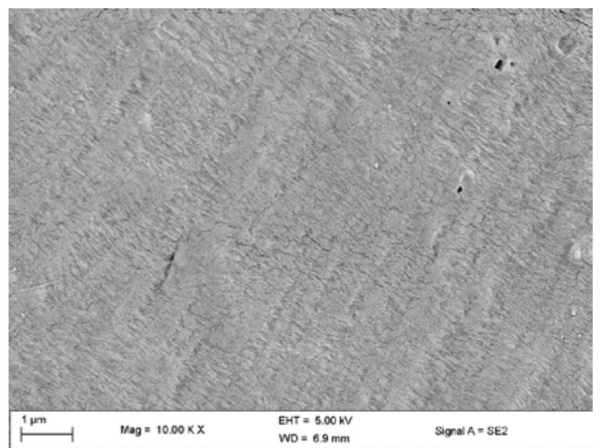

Fig. 15. Green LDPE control

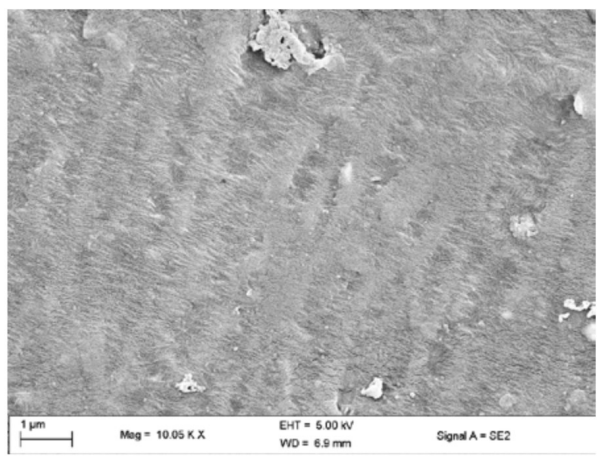

Fig. 17. Degradation in Surface sterilized green LDPE

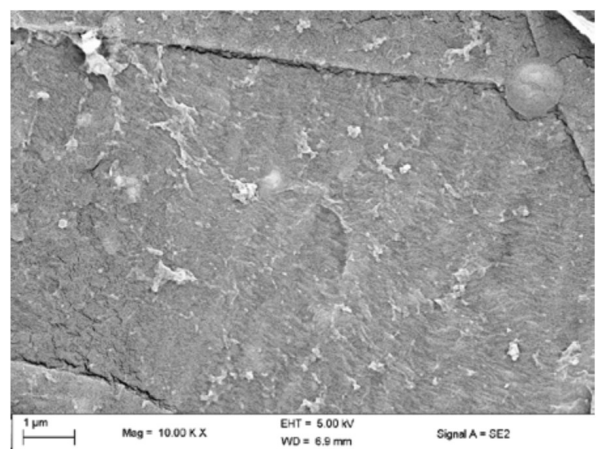

Fig. 19. Surafce erosion of Palmitic acid treated green LDPE

\section{DISCUSSION}

The current paper discusses about, the role of a culture medium and the role of palmitic acid in boosting the degradation of polyethylene.

A medium used to grow an organism plays a significant role since it decides the metabolic pathway of the organism. Potato dextrose medium is nutritionally rich and is a general purpose medium to grow molds. Therefore, A.oryzae naturally utilized the nutrients available in the medium and showed abundant growth on potato

Fig. 20. Water holding capacity of LDPE and HDPE 
dextrose medium. Though the fungal cultures were observed to grow on the polyethylene discs, the nutrients for the mycobial growth were obtained from the nutrient rich medium. This was not the case with Czapek dox medium which was not supplemented with any carbon source ${ }^{11,12}$. Hence it is a compulsion for the fungal isolate to survive on polyethylene. The degradation results of both LDPE and HDPE by A.oryzae followed the same principle.

According to Polyethylene chemical compatibility chart, palmitic acid has adverse and damaging effects on polyethylene and is incompatible with the polymer. Palmitic acid, a fatty acid, being non toxic in nature was used to coat the polyethylene films. Incubation of palmitic acid treated polyethylene films with A.oryzae resulted in a higher percentage of degradation than surface sterilized polyethylene. The results confirm the surfactant nature of palmitic acid ${ }^{13}$ which on pretreatment increases the water holding capacity of the polyethylene films and further supports the growth of A.oryzae ${ }^{14}$. A.oryzae is capable of producing several enzymes like amylase, cutinase, protease, esterase, peptidase, phosphatase etc $(15,16)$. Cutinase is an enzyme that can breakdown the plant polymer cutin, made of palmitic acid or stearic acid ${ }^{17}$. Consequently, A.oryzae capable of producing cutinase might have helped the organism in colonizing the polyethylene films coated with palmitic acid.

The biodegradation studies of HDPE and LDPE by A.oryzae showed higher percentage of degradation after palmitic acid pretreatment. FTIR studies showed the formation of carbonyl groups, alcohols, bending and stretching of $\mathrm{C}-\mathrm{H}$ bonds confirming the oxidation of polyethylene. SEM studies exposed cracks, fissures and fractures validating the physical damage caused by A.oryzae. The plastic films which are strictly hydrophobic were observed to absorb moisture after immersing them in water for 120 hours.

\section{CONCLUSION}

Aspergillus oryzae is a prospective organism for polyethylene biodegradation. The pretreatment of the polymer with palmitic acid supported the growth of A.oryzae which caused increase of water holding capacity in polyethylene films and further damage of the films led to mass loss, polymer surface erosion, formation and disappearances of functional groups in both kinds of polyethylene. The efficacy of the fungal strain enhanced on treating the films with palmitic acid which acted as a surfactant. The enzyme purification responsible for polyethylene degradation and its storage being complex and expensive, the non pathogenic Aspergillus oryzae, can be used for the degradation of polyethylene as used in food industry.

\section{ACKNOWLEDGEMENTS}

We thank DST-CURIE laboratory, SPMVV for providing us the instrumental facility required for the study.

\section{CONFLICT OF INTEREST}

On behalf of all authors, the corresponding author declares that there is no conflict of interest.

\section{REFERENCES}

1. RinkuVerma, K.S.Vinoda, M.Papireddy, A.N.S.Gowda, Toxic Pollutants from Plastic Waste- A Review. Procedia Environmental Sciences, 2016, Volume 35, Pages 701-708

2. Tirthankar Banerjee, Rajeev Kumar Srivastava, Yung-Tse Hung, Plastics waste management in India: An integrated solidwaste management approach, 2012, Handbook of Environmental and Waste Management Vol. 2

3. Yutaka Tokiwa, Buenaventurada P. Calabia, Charles U. Ugwu, and Seiichi Aiba, Biodegradability of Plastics, Int J Mol Sci. 2009 Sep; 10(9): 3722-3742

4. Anudurga Gajendiran, Sharmila Krishnamoorthy, and Jayanthi Abraham, Microbial degradation of low-density polyethylene (LDPE) by Aspergillus clavatus strain JASK1 isolated from landfill soil, 3 Biotech. 2016, Jun; 6(1): 52.

5. Chemical compatibility guide for polyethylene items: https://www.spilltech. com/wcsstore/ SpillTechUSCatalog AssetStore / Attachment / documents/ccg/POLYETHYLENE.pdf

6. Polyethylene/chemical compatibility guide. http://www.sunwestcontainer.com/pdf/ PolyChemCompatibility.pdf

7. Das MP, Kumar S, An approach to low-density polyethylene biodegradation by Bacillus amyloliquefaciens. 3Biotech,2015, 5:81-86

8. Kyaw B.M., Champakalakshmi R., Sakharkar M.K., Lim C.S., Sakharkar K.R., Biodegradation of Low Density Polythene (LDPE) by Pseudomonas Species. Indian J. 
Microbiol. 2012; 52:411-419. doi: 10.1007/ s12088-012-0250-6.

9. Ibiene, A. A., Stanley, H. O. \& Immanuel, O. M. Biodegradation of polyethylene by Bacillus sp. indigenous to the Niger Delta mangrove swamp. Nigeria. J. Biotech. 2013, 26, 68-79.

10. Ljerka Kratofil Krehula, Zvonimir Katanèiæ, Anita Ptièek Siroèiæ \& Zlata Hmjak-Murgic (), Weathering of High-Density Polyethylene-Wood Plastic Composites, Journal of Wood Chemistry and Technology, 2014, 34:1, 39-54..

11. Ojha, N. et al. Evaluation of HDPE and LDPE degradation by fungus, implemented by statistical optimization. Sci. Rep. 7, 2017, 39515; doi: 10.1038/srep39515.

12. E Munir et al, Plastic degrading fungi Trichoderma viride and Aspergillus nomius isolated from local landfill soil in Medan, IOP Conf. Ser.: Earth Environ. Sci. ,2018, 126012145

13. A.H. Tantawy et al, Surfactants Based on Palmitic Acid and Nitrogenous Bases for Removing Thin Oil Slicks from Water Surface. Chemistry Journal, 2012, 2(4), 136-145.

14. S. S. Radwan Y and Arwa H. Soliman, Arachidonic
Acid from Fungi Utilizing Fatty Acids with Shorter Chains as Sole Sources of Carbon and Energy, Journal of General Microbiology, 1988, 134, 387-393. Printed in Great Britain.

15. Crewther.W.G. \& Lennox, F.G., Enzymes of Aspergillus oryzae III. The sequence of appearance and some properties of the enzymes liberated during during growth. Australian J. Bio. Sci. 1953, 6:410-427.

16. Liu, Z., Gosser, Y., Baker, P. J., Ravee, Y., Lu, Z., Alemu, G., Li, H., Butterfoss, G. L., Kong, X. P., Gross, R., Montclare, J. K., Structural and functional studies of Aspergillus oryzae cutinase: enhanced thermostability and hydrolytic activity of synthetic ester and polyester degradation. Journal of the American Chemical Society, 2009, 131(43), 15711-6.

17. Acero, E. H., Ribitsch, D., Steinkellner, G., Gruber, K., Greimel, K., Eiteljoerg, I., Guebitz, G., Enzymatic surface hydrolysis of PET: effect of structural diversity on kinetic properties of cutinases from Thermobifida. Macromolecules, 2011, 44(12), 4632-4640. https://doi.org/10.1021/ ma200949p. 